
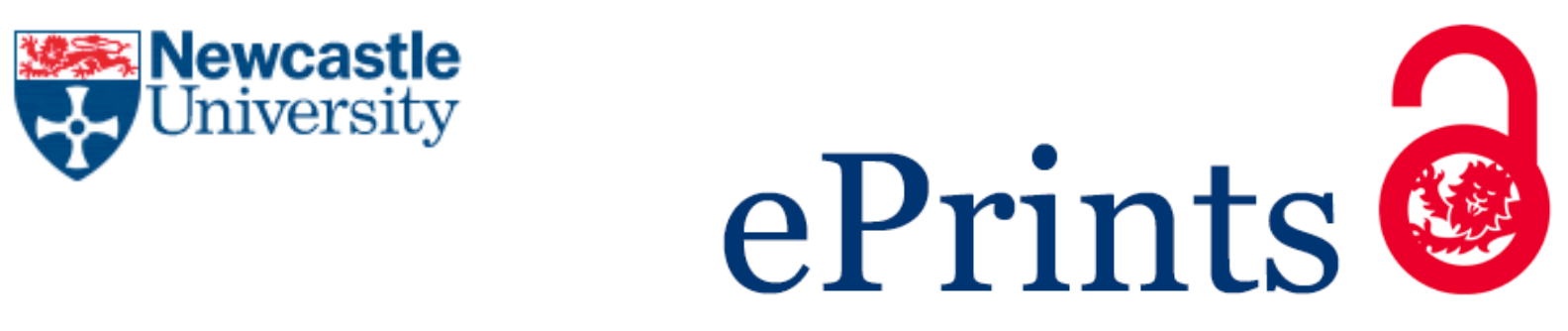

Powell JP, Batty P, González-Gil A, Palacin R.

Determining system-wide energy use in an established metro network. Proceedings of the Institution of Mechanical Engineers Part F: Rail and Rapid Transit 2016

DOI: $\underline{\text { http://dx.doi.org/10.1177/0954409716674748 }}$

\title{
Copyright:
}

This is the authors accepted manuscript of an article that has been published in its final definitive form by Sage Publications, 2016

DOI link to article:

http://dx.doi.org/10.1177/0954409716674748

Date deposited:

$14 / 12 / 2016$

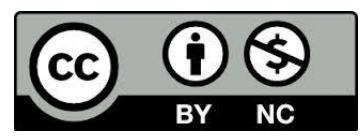

This work is licensed under a Creative Commons Attribution-NonCommercial 3.0 Unported License 
Special Issue Article

\section{Determining system-wide energy use in an established metro} network

Jonathan P Powell, Paul Batty, Arturo González-Gil and Roberto Palacín

NewRail - Centre for Railway Research, Newcastle University, UK

Corresponding author: Jonathan P Powell, NewRail - Centre for Railway Research,

School of Mechanical and Systems Engineering, Stephenson Building, Newcastle

University, Newcastle upon Tyne, NE1 7RU, UK.

Email: j.powell2@newcastle.ac.uk

\section{Abstract}

Energy is becoming an increasingly important topic in all transport systems. However, when evaluating alternative methods for optimisation of energy use, it is vital to obtain 
a thorough understanding of the energy flows within the system. While new systems generally have comprehensive automatic energy metering and monitoring of their components, there is much legacy infrastructure without this capability. This paper develops a methodology to determine a breakdown of energy use for the Tyne and Wear Metro, the results of which are compared to other railway systems. This is complemented by an investigation into the energy consumption of stabled rolling stock.

\section{Keywords}

Railway energy consumption, energy use breakdown, rail system, legacy infrastructure, Tyne and Wear Metro

\section{Introduction}

RSSB research ${ }^{1}$ has identified energy as one of five major 'game changer' issues facing the railway in Great Britain in the next few decades, with prices rising significantly and potential availability risks, due to small generating capacity margins and dwindling oil supplies. The conclusions from the report are that energy is likely to form a significantly greater proportion of the costs in the rail industry, rising from $4-5 \%$ to around $19 \%$ of the total in the next few decades. The strategy to mitigate this is threefold: increasing 
self-generation, protecting against the peak/off-peak energy price/availability disparity and implementing energy efficiency measures. However, variations in design, characteristics and operating environment between different railways means that measures to improve energy efficiency must be targeted to where they are most effective ${ }^{2}$. Considerable importance is therefore attached to having a good understanding of where energy is consumed within a given railway system.

The energy use of both vehicles and infrastructure should be considered over their entire life cycles, encompassing the energy consumed directly by the construction, operation, maintenance and disposal phases, and indirectly embodied in the materials and processes used. Several methods are available, depending on the objectives of the work in question. The relative merits of different approaches were considered in a paper by van Wee et al. ${ }^{3}$.

Life cycle assessments that compare different transport modes for both passengers and freight have been the subject of previous detailed studies, for example in Europe ${ }^{4}$ and the USA ${ }^{5,6}$. The broad trends are all reasonably similar; rail outperforms both road and air for energy efficiency (the energy consumed per passenger-km or freight.tonne-km), and has a similar performance to water transport. The investigation of individual railway systems is required to draw more specific conclusions, given the potential variation between different rail systems that was highlighted above. 
The majority of the railway system life cycle energy assessments in recent years have focussed on high-speed rail, in response to the need for policy guidance. A study of the ecology profile of the Deutsche Bahn-operated ICE services was carried out by von Rozycki et al. ${ }^{7}$. The majority of the life cycle energy use was accounted for by traction energy and passenger trips to or from the station, and to a lesser extent the embodied energy from infrastructure. The most important factors that influence energy use are therefore the number of trains running, their duty cycles and load factors, and a smaller (but still notable) contribution from the number and size of major civil works such as bridges and tunnels. Such findings have been echoed in other high-speed rail infrastructure studies in Sweden ${ }^{8}$ and Great Britain ${ }^{9}$. There are plenty of examples of built environment literature now available that detail the methodologies available for calculating the life cycle energy demand of different elements of the railway system ${ }^{9-16}$.

It can be concluded from the above literature that approximately two-thirds of the energy consumed by railway systems is accounted for by direct operational energy use, itself dominated by traction energy. Differences in the exact breakdown of energy use vary according to the individual characteristics of the railway system considered, the extent of the analysis and the inherent uncertainties in the data used. Nevertheless, the broad trends are similar and as such, this paper focusses on understanding how direct operational energy is used in rail systems. The Tyne and Wear Metro in the north-east of England is used as a case study, with comparisons made to other rail systems. These 
comparisons highlighted that there are relatively few investigations into the energy consumption of stabled rolling stock in existing literature. As such, this area is considered in more detail to help support future work to improve energy efficiency.

\section{Establishing the direct operational energy consumption of legacy infrastructure}

The Tyne and Wear Metro

Energy metering for different subsystems within a railway system provides the data required for analysis of energy use, and the general introduction of computer control and monitoring systems means that this practice has become standard for new build infrastructure. However, this level of information is not necessarily available for legacy infrastructure, and further investigations are required to derive sufficient data to effectively target measures to improve energy efficiency. The Tyne and Wear Metro, a light rail system centred on Newcastle upon Tyne in the north-east of England, is used as a case study for this paper.

The first $54 \mathrm{~km}$ of the network were opened progressively from 1980, using a combination of existing heavy rail alignments converted to Metro use, new tunnels through the centre of Newcastle and Gateshead, and a new bridge across the river Tyne. 
The network was subsequently extended by $3 \mathrm{~km}$ to Newcastle International Airport in 1991 and a further $19 \mathrm{~km}$ to South Hylton in 2002, the latter extension sharing tracks with heavy rail services between Pelaw and Sunderland ${ }^{17,18}$. Previously, there had also been occasional mixed working of heavy rail (freight) and light rail Metro services between Bank Foot and Benton in the 1980s. The complete network was analysed for this paper.

The Metro-only infrastructure is owned and maintained by Nexus, the local government Passenger Transport Executive, while Network Rail is the infrastructure manager for the section between Pelaw and South Hylton. All Metro train operations are contracted to Deutsche Bahn (DBTW) under a concession agreement, which runs until April 2017.

The original fleet of 90 twin-section Metrocars remain in service today, and operate services in pairs. They were refurbished between 1995 and 2000, and life extension work was carried out between 2010 and 2015, with the intention of keeping the trains in service until the mid-2020s. Traction is provided by two $185 \mathrm{~kW}$ series-wound DC motors per Metrocar, with air/oil camshaft resistance control, and a combination of friction and rheostatic braking. Waste heat is recovered from the resistors for saloon heating, supplemented by an auxiliary heater when required; no air conditioning is fitted.

The trains are manually driven, with a mix of two, three and four-aspect lineside colour light signalling controlled by track circuits. The Indusi train protection system is fitted 
across the network, as well as AWS and TPWS on the section between Pelaw and Sunderland.

The system is electrified using overhead wires at $1500 \mathrm{~V} \mathrm{DC}$, fed from ten substations connected to the National Grid. There is an internal $11 \mathrm{kV}$ network that covers the central underground section in Newcastle; this feeds two further traction substations, as well as signalling supplies in the tunnels and seven passenger stations. There are seven other stations around the network that are connected directly to adjacent traction substations, while the remaining 46 stations are connected directly to National Grid local distribution networks. The original electrical network was described in a paper by Prickett ${ }^{19}$; subsequently a second transformer/rectifier was added at Kenton Bank for the airport extension, and for the Sunderland extension new substations were built at Fellgate, Seaburn and Pallion. As well as the electrical supplies, a small amount of gas is used in Gosforth depot and in the control centre at South Gosforth station.

\section{Methodology}

Energy consumption in the Tyne and Wear Metro system between 1 April 2012 and 31 March 2013 was analysed in detail, with the analysis broken down and classified into traction, depot, station, infrastructure and office use. These subsystems were chosen to allow a direct comparison with previous studies of other railway systems, discussed in later sections of the paper. There are some energy meters in place, but not all of these 
subsystems are metered individually, and the level of information available varied from one subsystem to another. Different calculation methods were required for each individual subsystem as a result, and the overarching methodology of this paper can therefore be described as follows:

- Traction energy use was estimated from an energy meter fitted to one of the Metrocars, using fleet mileage records to extrapolate to all 90 Metrocars, and an estimate of power supply system losses.

- Depot energy use was extrapolated from meter readings covering part of the period studied.

- Some of the stations are metered, and a four-week survey of all stations was carried out in 2012. These sources were analysed together to estimate the annual consumption for all stations.

- The infrastructure energy use was estimated from signalling and substation equipment specifications and duty cycles.

- The office data was derived from a combination of the metered readings at South Gosforth during the station survey, and UK Government benchmarks for the city centre offices. 
- The overall energy consumption was calculated as the sum of each subsystem, and compared against the total annual energy bill from the energy suppliers.

The rest of this section presents the results, including a more detailed description of the specific methods for each subsystem. The following sections compare these results against other railway systems in Great Britain.

\section{Results}

Overview. The estimated overall energy consumption is illustrated in Figure 1. The minimum and maximum values were derived from the uncertainties identified for each of the subsystems during their respective calculations. These calculations are described individually for each subsystem in more detail below. Together, these results give the minimum and maximum estimate for the overall system energy consumption. The central estimate is defined as the total derived from the nominal estimated value for each subsystem, and does not necessarily correspond to the midpoint of the range between the minimum and maximum estimates. 


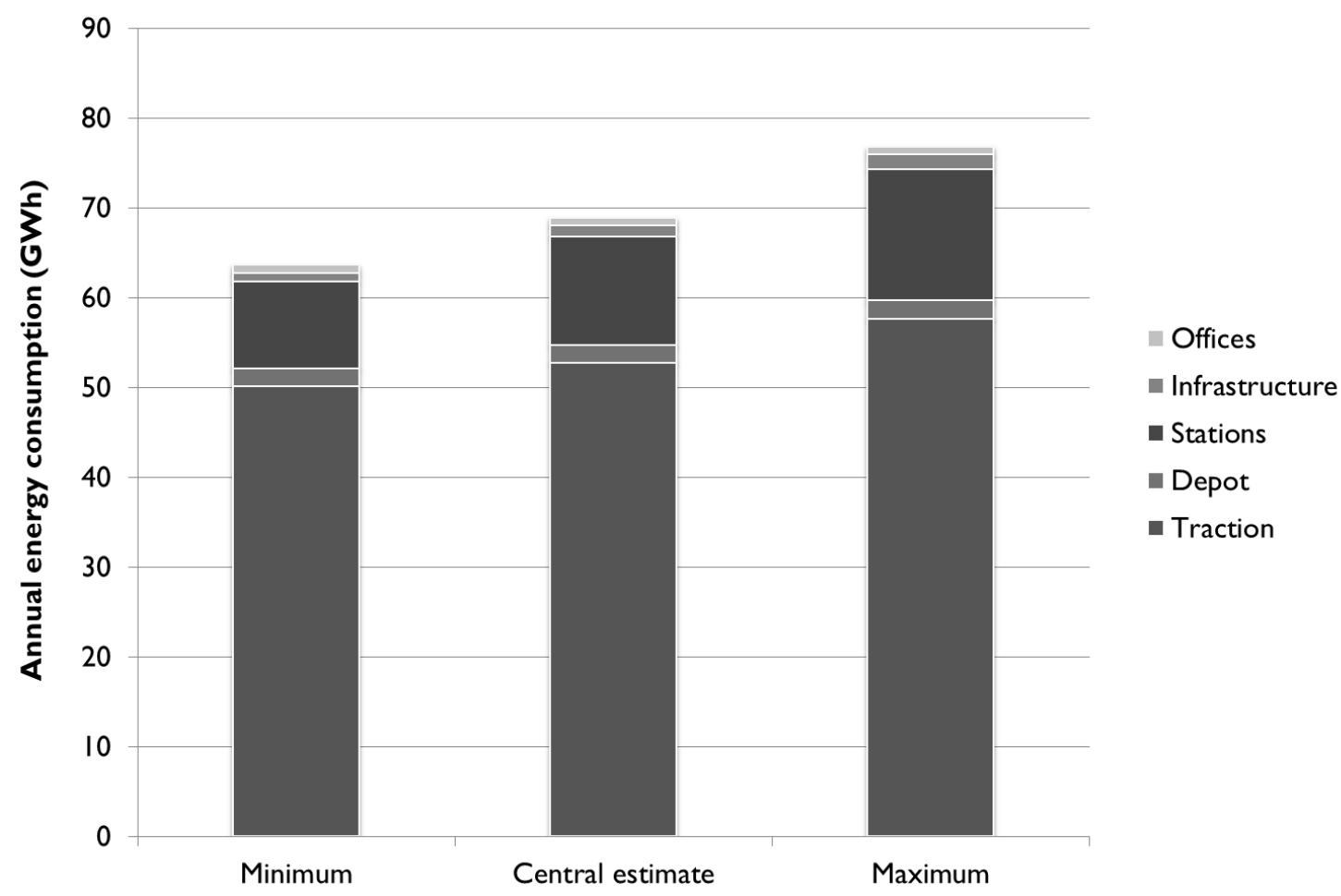

Figure 1. Estimates for direct operational energy use of the Tyne and Wear Metro

The total energy consumption predicted from the estimates for each subsystem matched the billed value of $69 \mathrm{GWh}$ closely, comfortably inside the margin of uncertainty calculated for all of subsystems. Further details of how the estimates for each of these subsystems were derived are set out in the following sections; all values are given to two significant figures.

Traction. Seven Metrocars were fitted with different designs of energy meter at different times during 2012. Metrocar number 4067 was already fitted with an energy meter at the start of the period being analysed, and its energy consumption was therefore used as 
a basis for estimating the fleet's consumption. The meter measured the speed, line voltage, current and power draw of Metrocar 4067 every second, and this was compared against the corresponding distance for both the unit and the overall fleet from the maintenance records/timetabled diagrams. This gave a total energy use of $53 \mathrm{GWh}$ for the energy consumed by the Metrocars for traction, with an uncertainty of approximately $2-3 \%$ from the energy meter measurement accuracy for energy and distance calculations. There were also small differences between the total distance measured by the energy meter and the maintenance records/timetabled diagrams. There are also further losses in the power supply system. To estimate these, the rolling stock current draw characteristics were taken from the metered data, while overhead conductor resistances and substation distances were provided by DBTW/Nexus. This allowed average, best-case and worst-case losses to be estimated, based on the current draw at different distances from lineside substations. To determine the power supply system losses more accurately would require detailed modelling that was outside the scope of this study. As a result, the potential range of values was estimated at 50-58 GWh.

Depot. The $11 \mathrm{kV} / 415 \mathrm{~V}$ transformer that supplies the depot was replaced in 2011 and an energy meter fitted. Readings were taken at four-week intervals from July 2012.The average consumption in each four-week interval between July 2012 and March 2013 was calculated from these readings, and the intervals with the minimum and maximum 
consumption were also identified. The full year consumption was then estimated from the known readings added to either the minimum, average or maximum estimate for the missing period between April 2012 and July 2012. This resulted in an estimated energy consumption of approximately $1.8 \mathrm{GWh}$ for the full year, with a potential range of $-3.4 \%$ to $+4.9 \%$ (the percentage is given to provide more information than quoting the absolute values of 1.8 to $1.9 \mathrm{GWh}$ to two significant figures).

Stations. The 46 stations fed from the National Grid directly are individually metered, and the total energy consumption of $4.4 \mathrm{GWh}$ is therefore known. The exception is South Gosforth - refer to the section on 'Offices' below for details. For the stations fed directly from the traction substations, data from a survey of all of the stations in the network carried out by DBTW/Nexus over several months in 2012 was used. This survey used portable meters to measure the load on the main intake position at each station for a seven day period. The survey results for the 46 individually metered stations were compared against their billed energy consumption, which gave an indication of the likely accuracy of the survey data for the other stations. Secondly, the monthly billing data for these stations was used to estimate how energy consumption at stations changes throughout the year in response to seasonal variations in temperature and hours of daylight. This information was used to estimate the full year consumption for the remaining stations from the seven days of survey data. This allowed an estimate of $8.1 \mathrm{GWh}$ to be made for the total annual energy consumption of the 14 stations fed 
directly from traction substations. The survey data did not necessarily match the metered data closely for all 46 stations, and seasonal variations also didn't necessarily follow the same pattern in each case. These differences were used to derive minimum and maximum likely energy consumption values, and the potential range of the values for the remaining 14 stations is between 5.5 and $11 \mathrm{GWh}$. This gives a total average energy consumption of $12 \mathrm{GWh}$ for stations, with a potential range of 9.8-15 GWh.

Infrastructure. The principal infrastructure components on the Tyne and Wear Metro are signalling and electrical switchgear/auxiliary equipment in the traction substations. The signalling energy consumption was determined from typical equipment specifications and the number of signals on the network:

- The power consumption for signal lamps is $30 \mathrm{~W}$.

- Track circuit power supplies vary between a few watts to a couple of tens of watts, depending on design and block length.

- The Indusi balises are passive, energised by the aerials on the Metrocars, and therefore draw no power from the lineside.

- On the shared section to Sunderland, AWS magnets consume around $10 \mathrm{~W}$ in operation, and the TPWS system typically tens of watts. 
Therefore, a nominal estimate of $100 \mathrm{~W}$ per signal was made, with a possible range of 50 to $200 \mathrm{~W}$. Point motors draw more power than signalling equipment, at approximately $150 \mathrm{~W}$, but the duty is very intermittent. Level crossing equipment consumes a similar amount of power in operation but the duty is also intermittent, and as a result the power consumed by point motors and level crossings may be considered to be negligible by comparison with the range of uncertainty in the signalling estimates. The energy consumed by the equipment in the traction substations was estimated from information provided by Network Rail, taking an average for substation energy consumption and multiplying this by the number of substations on the Metro network. This gives a total estimate of $1.2 \mathrm{GWh}$ for infrastructure, although the approximations result in a large range of uncertainty of 0.5 to $1.7 \mathrm{GWh}$. The split between signalling equipment and traction substation equipment appears approximately equal, although the magnitude of the range of uncertainty prevents more detailed analysis. Nevertheless, it should be noted that this range is small by comparison with the energy consumed in the whole system.

Offices. The offices category includes the Gosforth control centre and the administrative offices in Newcastle city centre. The metered energy consumption at South Gosforth station was approximately ten times that of the average consumption of other stations with a similar design. Therefore, this average was used for the consumption of the station, and the remainder of the metered energy consumption was assumed to be the 
power consumed by the control centre. The energy consumption of the city centre offices was estimated from the floor area, using the UK Government ECG 19 benchmarks ${ }^{20}$ for a typical office building of similar design. This gave an estimate of $0.9 \mathrm{GWh}$, with a range of uncertainty of 0.8 to $1.1 \mathrm{GWh}$.

\section{Comparison with other railway systems}

\section{Methodology}

Having estimated the breakdown of energy use between different subsystems in the Tyne and Wear Metro, the results were compared against other rail systems in Great Britain, to investigate how the characteristics of these systems influence the breakdown of energy consumption. The main line network and London Underground were chosen, as the characteristics of the Tyne and Wear Metro are closer to these systems than other urban rail systems (Glasgow Subway, Docklands Light Railway and tram networks). Data were derived from analysis of contemporary carbon footprint reports: a Transport for London summary of London Underground ${ }^{21}$ and an RSSB research report into the carbon footprint of the national rail network in Great Britain ${ }^{22}$.

Although carbon emissions do not map directly to energy consumption, the direct operational energy use identified as contributing to the carbon footprint can be extracted from the reports, and an approximate overall breakdown for each system was therefore inferred on this basis. 


\section{Results}

In total for $2008 / 2009$, the mainline railway used 4.4 TWh of electricity (of which 2.9 TWh was for traction), 692 million litres of diesel fuel and 417 million $\mathrm{kWh}$ of gas. By contrast, London Underground consumed approximately $1 \mathrm{TWh}$ of electricity, and a relatively small amount of gas. To obtain the overall energy consumption on a like-forlike basis between the different sources, the Greenhouse Gas Conversion Factors for Company Reporting ${ }^{23}$ provided by the UK Government were used. The comparison with the Tyne and Wear Metro is illustrated in Figure 2. 


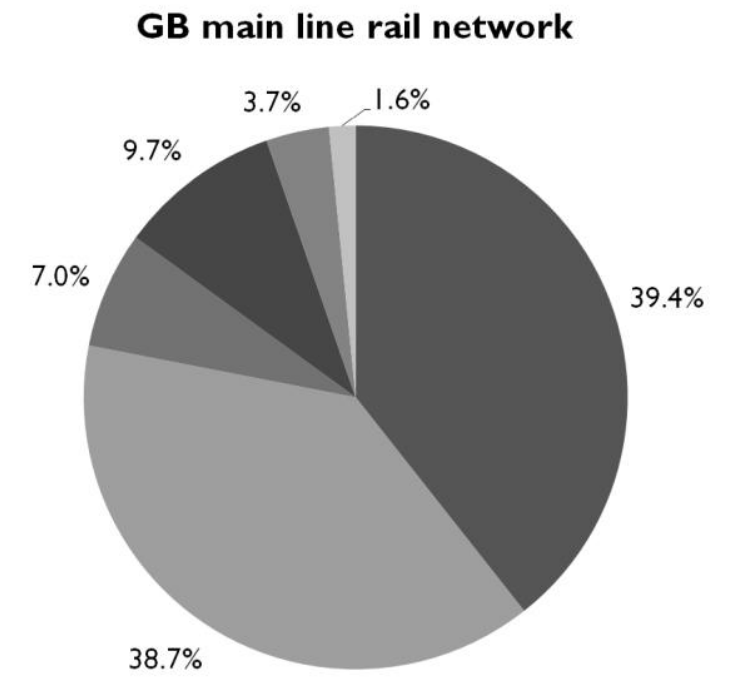

London Underground

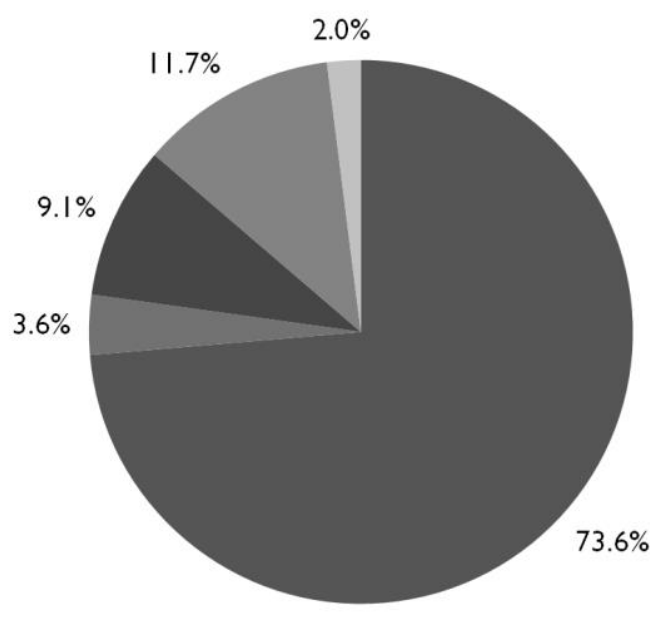

- Traction (electricity)

- Traction (diesel)

Depots

- Stations

- Infrastructure

Offices
Tyne and Wear Metro

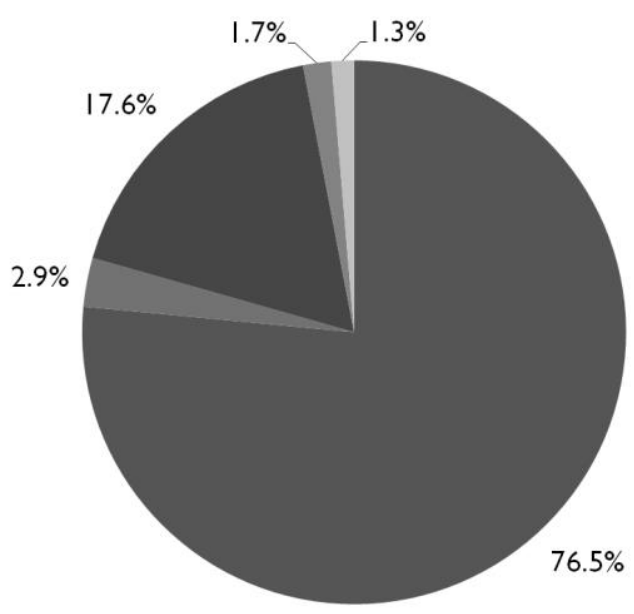

Figure 2. Direct operational energy use in three railway systems in Great Britain

The traction energy consumptions for each of the three systems are all very similar, with $78.1 \%, 73.6 \%$ and $76.5 \%$ for the Great Britain mainline network, the London Underground network and the Tyne and Wear Metro respectively. This is remarkably 
consistent, given the differences between the systems. As such, data from other railway systems across the world was considered as a point of comparison. A study of JR East in Japan suggested that traction energy accounted for $70.5 \%$ of the total energy used for direct operation of the railway ${ }^{24}$. It should be noted however that JR East has developed a significant amount of housing, retail and entertainment real estate (both at stations, and also alongside tracks) ${ }^{25}$. When the energy consumed by these extra station developments is taken into account, traction energy only accounted for $61.1 \%$ of the total energy consumption. By contrast, a study of Indian Railways suggested that around $93 \%$ of the energy consumption is accounted for by traction energy ${ }^{26}$. Anderson et al. ${ }^{27}$ provide a further set of 24 (anonymised) examples of the split between traction and non-traction energy use in metro systems across the world, which suggests that twothirds of the direct energy use accounted for by traction on average.

\section{Analysis and discussion}

London Underground runs a very high density service over its $402 \mathrm{~km}$ network, with many stop/start cycles. Approximately $45 \%$ of this is in tunnels, with a high resistance to motion. Infrastructure also consumes more energy on the London Underground than other networks, on account of the necessity for tunnel ventilation fans and groundwater pumps for the extensive tunnel network ${ }^{28}$. The GB mainline network has a lower train service density than London Underground, with proportionally very few underground 
stations or tunnels; much of the infrastructure is also older than the Tyne and Wear Metro.

The energy consumed by London Underground stations varies significantly over the network, but in total comprises $9.1 \%$ of the overall system consumption. As with the infrastructure, the ventilation and temperature control of the underground stations requires a significant amount of energy. In addition, access generally requires a greater number of escalators and lifts than above-ground stations. Within the London Underground system, there are 408 escalators and 112 lifts, with an average of 1.48 escalators and 0.41 lifts per station. By contrast, the Tyne and Wear Metro has 0.58 escalators and 0.58 lifts per station, yet $17.6 \%$ of the total energy consumption is taken up by stations. Out of the 60 stations on the network, the 11 underground stations (12 including Sunderland, owned by Network Rail) account for around two-thirds of the total station energy consumption. All 35 escalators and 24 of the 35 lifts in the network operate in these stations, and they also require ventilation. As such, the implementation of energy efficiency measures within these underground stations is an area worth future consideration, and is an ongoing area of work for the Tyne and Wear Metro (slowing escalators for example). It is also likely that the Tyne and Wear Metro stations consume proportionally more of the total energy consumption than the London Underground due to the less intensive train service. The mainline network has both a lower train service 
density and a lower station density than the London Underground, which offsets the reduced consumption of above-ground stations.

The energy consumption of depots is highest on the mainline, on account of the relatively less intense train service and a greater number of heavy maintenance sites and remote sidings. One of the problems encountered in the literature is that it is not always clear how different systems categorise the energy supplied to stabled trains within depots, since this can be considered as either traction energy or depot energy. Given the level of variance between the energy consumptions of depots in this study, this merits further investigation into the effects of the energy consumed by stabled trains on the overall energy consumption.

\section{Energy consumption during stabling hours}

Due to the fleet size of the Tyne and Wear Metro, many vehicles are stabled outdoors at Gosforth depot, with others stabled in the inspection shop (which is heated) and running shed (effectively unheated). In principle, all of the Metrocar's auxiliary systems remain in operation when stabled, unless isolated from the overhead power supply for certain maintenance tasks. This means that the Metrocar heating maintains the target interior temperature to the same level as it is in service throughout stabling. A detailed investigation of energy meter data collected from on board the aforementioned Metrocar number 4067 was carried out, and further details of this study can be found in Powell et 
al. ${ }^{29}$. In summary, the overhead line voltage, the current drawn from the overhead line, and the output voltage from the motor-alternator set that powers some of the auxiliaries were analysed to determine energy consumption while stabled. These data were then compared with historical climate data to understand the relationship between the ambient temperature and the vehicle's energy consumption while stabled, and the factors that affect it.

It was found that, of the annual energy consumption of a Tyne and Wear Metrocar, approximately $11 \%$ can be attributed to on-board auxiliary systems while the vehicle is stabled. The greatest contributor to this amount was found to be the heating; shown to be responsible for approximately $45 \%$ of this consumption, with the lighting and compressed air systems contributing $10 \%$ and $4 \%$ respectively to the overall figure. A combination of other energy components, such as fans and control circuits, represent the remaining $41 \%$ of the total stabled energy consumption. This is illustrated in Figure 3. 


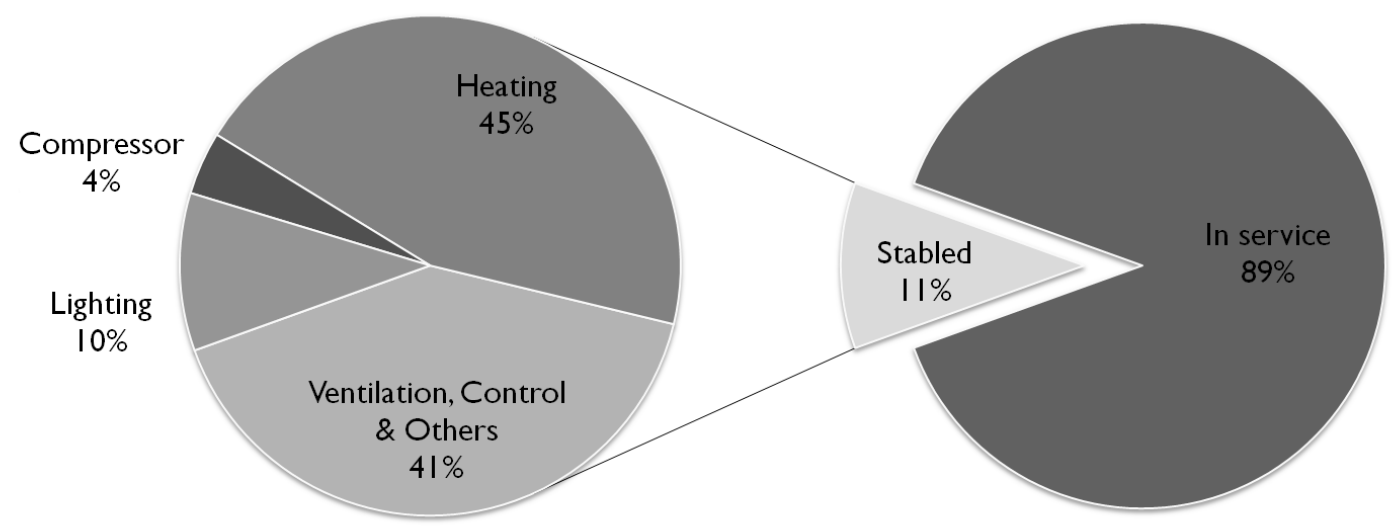

Figure 3. Breakdown of the traction energy use of a Tyne and Wear Metrocar ${ }^{29}$

If these results are applied to the central estimate of the overall breakdown illustrated in Figure 1, the energy consumed by stabled Metrocars accounts for around $8 \%$ of the total system energy consumption. This is more than all of the above-ground stations together, or alternatively, more than the combined consumption of the depot, infrastructure and offices.

\section{Conclusions}

Understanding the breakdown of energy consumption within rail systems is key when attempting to focus investment on energy efficiency improvements to a system. This investigation described a methodology for rail systems without automated energy metering capabilities to achieve a greater understanding of this breakdown, through the 
use of a combination of measurements and modelling to provide an indication of the energy usage by the various sub-systems.

This methodology was applied to a case study of the Tyne and Wear Metro, and demonstrated that underground stations are particularly important in this case, accounting for approximately $12 \%$ of the total system energy consumption, a significantly greater proportion than other rail systems. Likewise, the energy consumed by stabled vehicles was also shown to be significant, at around $8 \%$ of the system total.

The comparison between different railway systems has also provided insight into how the relative energy consumption of different subsystems differs, depending on the characteristics of a particular system under investigation. The methods developed can be applied to other systems, to effectively target measures that can help ensure rail systems retain their environmental superiority over other mass transit modes.

\section{Acknowledgements}

The authors would like to thank DBTW for their support during this investigation.

\section{Abbreviations}

AWS - Automatic Warning System

DB - $\quad$ Deutsche Bahn

DBTW - $\quad$ DB Regio Tyne \& Wear Ltd. 


$\begin{array}{lll}\text { GB } \quad-\quad & \text { Great Britain } \\ \text { ICE } \quad-\quad & \text { Intercity-Express } \\ \text { Nexus - } & \text { Tyne and Wear Metro infrastructure owner/maintainer } \\ \text { RSSB - } & \text { Rail Safety and Standards Board } \\ \text { TPWS - } & \text { Train Protection and Warning System }\end{array}$

\section{References}

1. Energy Game Changer - Macro energy risks affecting the railway in Great Britain. London: Rail Safety and Standards Board; 2012. RSSB Project Report T966.

2. González-Gil A, Palacin R, Batty P and Powell JP. A systems approach to reduce urban rail energy consumption. Energy Conversion and Management. 2014; 80: 509-24.

3. van Wee $\mathrm{B}$, Janse $\mathrm{P}$ and van den Brink R. Comparing energy use and environmental performance of land transport modes. Transport Reviews. 2005; 25: 3-24. 4. Bos AJM. Direction indirect - The indirect energy requirements and emissions from freight transport. Doctoral Thesis; Rijksuniversiteit Groningen; 1998.

5. Facanha C. Life-cycle air emissions inventory of freight transportation in the United States. Doctoral thesis; University of California at Berkeley; 2006. 
6. Chester MV. Life-cycle Environmental Inventory of Passenger Transportation in the United States. Doctoral thesis; University of California at Berkeley; 2008.

7. von Rozycki C, Koeser H and Schwarz H. Ecology profile of the German highspeed rail passenger transport system ICE. Int J LCA. 2003; 8: 83-91.

8. Åkerman J. The role of high-speed rail in mitigating climate change - The Swedish case Europabanan from a life cycle perspective. Transportation Research Part D: Transport and Environment. 2011; 16: 208-17.

9. Chau C, Soga K, O'Riordan N and Nicholson D. Embodied energy evaluation for sections of the UK Channel Tunnel rail link. Proceedings of the ICE-Geotechnical Engineering. 2012; 165: 65-81.

10. Miyauchi $\mathrm{T}$, Nagatomo $\mathrm{T}$, Tsujimura $\mathrm{T}$ and Tsuchiya $\mathrm{H}$. Fundamental Investigations of LCA of Shinkansen Vehicles. Quarterly Report of RTRI. 1999; 40: 204-9.

11. Struckl W, Stribersky A and Gunselmann W. Life cycle analysis of the energy consumption of a rail vehicle. Workshop of the Allianz pro Schiene. 2006 Sep 19. Berlin, Germany.

12. Hammond GP and Jones CI. Embodied energy and carbon in construction materials. Proceedings of the ICE - Energy. 2008; 161: 87-98.

13. Kiani M, Parry T and Ceney H. Environmental life-cycle assessment of railway track beds. Proceedings of the ICE-Engineering Sustainability. 2008; 161: 135-42. 
14. Jorge RS, Hawkins TR and Hertwich EG. Life cycle assessment of electricity transmission and distribution—part 1: power lines and cables. Int J LCA. 2012; 17: 9-15. 15. Jorge RS, Hawkins TR and Hertwich EG. Life cycle assessment of electricity transmission and distribution-part 2: transformers and substation equipment. Int J LCA. 2012; 17: 184-91.

16. Wang XC and Sanders L. Energy consumption and carbon footprint of highspeed rail projects: Using CAHSR and FHSR as examples. Proceedings of the Institution of Mechanical Engineers, Part F: Journal of Rail and Rapid Transit. 2012; 226: $26-35$.

17. Howard DF. Tyne and Wear Metro - A modern rapid transit system. Proceedings of the Institution of Mechanical Engineers. 1976; 190: 121-36.

18. Mackay KR. Sunderland Metro - Challenge and Opportunity. Proceedings of the ICE-Municipal Engineer. 1999; 133: 53-63.

19. Prickett BR. Electrification of the Tyne and Wear Metro. Electric Power Applications, IEE Proceedings B. 1981; 128: 81-91.

20. Energy Consumption Guide 19 - Energy use in offices. London: Department for Environment, Food and Rural Affairs; 2003.

21. LU Carbon Footprint Report 2008. London: Transport for London; 2009.

22. Whole life carbon footprint of the rail industry. London: Rail Safety and Standards Board; 2010. RSSB Project Report T913. 
23. Guidelines to Defra's Greenhouse Gas Conversion Factors for Company Reporting. London: Department for Environment, Food and Rural Affairs; 2008.

24. Shinbo M. Railway System Optimization Seen from an Energy Management Perspective. JR EAST Technical Review. 2012; 23: 5-8.

25. van de Velde DM. Learning from the Japanese railways: Experience in the Netherlands. Policy and Society. 2013; 32: 143-61.

26. Kumar S. The Voice of Members - Indian Railways. Energy Efficiency Days. 2014 Jun 16-19. Antwerp, Belgium.

27. Anderson R, Maxwell R and Harris NG. Maximizing the potential for metros to reduce energy consumption and deliver low-carbon transportation in cities. MetroRail Asia. 2009 Sep 29. Delhi, India

28. Ampofo F, Maidment $\mathrm{G}$ and Missenden J. Underground railway environment in the UK Part 3: Methods of delivering cooling. Applied Thermal Engineering. 2004; 24: 647-59.

29. Powell JP, González-Gil A and Palacin R. Experimental assessment of the energy consumption of urban rail vehicles during stabling hours: Influence of ambient temperature. Applied Thermal Engineering. 2014; 66: 541-7. 